\title{
PRODUCTS OF RADIAL DERIVATIVE AND MULTIPLICATION OPERATOR BETWEEN MIXED NORM SPACES AND ZYGMUND-TYPE SPACES ON THE UNIT BALL
}

\author{
JiE ZHOU AND YONGMIN LIU
}

Abstract. In this paper, we obtain some characterizations of the boundedness and compactness of the products of the radial derivative and multiplication operator $\mathscr{R} M_{u}$ between mixed norm spaces $H(p, q, \phi)$ and Zygmund-type spaces on the unit ball.

Mathematics subject classification (2010): 47B38, 47G10, 32A10, 32A18.

Keywords and phrases: Unit ball, mixed norm space, Zygmund-type space, radial derivative operator, multiplication operator.

\section{REFERENCES}

[1] Z. Hu, Extended Cesàro operators on mixed norm spaces, Proc. Amer. Math. Soc. 131, 7 (2003), 2171-2179 (electronic).

[2] B. Li, C. OUYANG, Higher radial derivative of functions of $Q_{p}$ spaces and its applications, J. Math. Anal. Appl. 327, 2 (2007), 1257-1272.

[3] S. Li, S. STEVIĆ, Generalized composition operators on Zygmund spaces and Bloch type spaces, J. Math. Anal. Appl. 338, 2 (2008), 1282-1295.

[4] S. Li, S. STEviĆ, Products of Volterra type operator and composition operator from $H^{\infty}$ and Bloch spaces to Zygmund spaces, J. Math. Anal. Appl. 345, 1 (2008), 40-52.

[5] S. LI, S. STEVIĆ, Composition followed by differentiation between $H^{\infty}$ and $\alpha$-Bloch spaces (English summary), Houston J. Math. 35, 1 (2009), 327-340.

[6] S. LI, S. STEVIĆ, Integral-type operators from Bloch-type spaces to Zygmund-type spaces, Appl. Math. Comput. 215, 2 (2009), 464-473.

[7] S. LI, S. STEvić, Products of composition and differentiation operators from Zygmund spaces to Bloch spaces and Bers spaces, Appl. Math. Comput. 217 (2010), 3144-3154.

[8] Y. LIU, Boundedness of the Bergman type operators on mixed norm spaces, Proc. Amer. Math. Soc. 130, 8 (2002), 2363-2367 (electronic).

[9] Y. LiU, Y. YU, Weighted differentiation composition operators from mixed-norm to Zygmund spaces, Numer. Funct. Anal. Optim. 31, 8 (2010), 936-954.

[10] Y. LiU, Y. YU, On compactness for iterated commutators, Acta Math. Sci. Ser. B Engl. Ed. 31B, 2 (2011), 491-500.

[11] Y. LIU, Y. YU, Composition followed by differentiation between $H^{\infty}$ and Zygmund spaces, Complex. Anal. Oper. Theory 6, 1 (2012), 121-137.

[12] W. Rudin, Function Theory in the Unit Ball of $\mathbb{C}^{n}$, Springer-Verlag, New York-Berlin, 1980.

[13] A.L. Shields, D.L. Williams, Bounded projections, duality, and multipliers in spaces of analytic functions, Trans. Amer. Math. Soc. 162 (1971), 287-302.

[14] S. STEVIĆ, Boundedness and compactness of an integral operator on mixed norm spaces on the polydisc, Siberian Math. J. 48, 3 (2007), 559-569.

[15] S. STEVIĆ, Weighted composition operators between mixed norm spaces and $H_{\alpha}^{\infty}$ spaces in the unit ball, J. Inequal. Appl. 2007 (2007), Art. ID 28629, 9 pp. doi:10.1155/2007/28629.

[16] S. STEVIĆ, Weighted differentiation composition operators from mixed-norm spaces to weighted-type spaces, Appl. Math. Comput. 211, 1 (2009), 222-233. 
[17] S. STEVIĆ, On an integral operator from the Zygmund space to the Bloch-type space on the unit ball, Glasg. J. Math. 51 (2009), 275-287.

[18] S. STEVIĆ, On an integral-type operator from logarithmic Bloch-type and mixed-norm spaces to Bloch-type spaces, Nonlinear Anal. 71, 12 (2009), 6323-6342.

[19] S. STEvić, On a new integral-type operator from the Bloch space to Bloch-type spaces on the unit ball, J. Math. Anal. Appl. 354, 2 (2009), 426-434.

[20] S. STEVIĆ, On an integral-type operator from logarithmic Bloch-type spaces to mixed-norm spaces on the unit ball, Appl. Math. Comput. 215, 11 (2010), 3817-3823.

[21] S. STEVIĆ, On operator $P_{\varphi}^{g}$ from the logarithmic Bloch-type space to the mixed-norm space on the unit ball, Appl. Math. Comput. 215, 12 (2010), 4248-4255.

[22] S. STEVIĆ, Extended Cesàro operators between mixed-norm spaces and Bloch-type spaces in the unit ball, Houston J. Math. 36, 3 (2010), 843-858.

[23] S. STEvić, Composition followed by differentiation from $H^{\infty}$ and the Bloch space to $n$th weightedtype spaces on the unit disk, Appl. Math. Comput. 216, 12 (2010), 3450-3458.

[24] S. STEVIĆ, On an integral-type operator from Zygmund-type spaces to mixed-norm spaces on the unit ball, Abstr. Appl. Anal. 2010 (2010), Article ID 198608, 7 pp..

[25] S. STEVIĆ, Weighted iterated radial composition operators between some spaces of holomorphic functions on the unit ball, Abstr. Appl. Anal. 2010 (2010), Article ID 801264, 14 pp..

[26] S. STEVIĆ, On an integral operator between Bloch-type spaces on the unit ball, Bull. Sci. Math. 134 (2010), 329-339.

[27] S. STEVIĆ, On a product-type operator from Bloch spaces to weighted-type spaces on the unit ball, Appl. Math. Comput. 217 (2011), 5930-5935.

[28] S. STEVIĆ, On some integral-type operators between a general space and Bloch-type spaces, Appl. Math. Comput. 218, 6 (2011), 2600-2618.

[29] S. STEVIĆ, Boundedness and compactness of an integral-type operator from Bloch-type spaces with normal weights to $F(p, q, s)$ space, Appl. Math. Comput. 218, 9 (2012), 5414-5421.

[30] S. STEVIĆ, Weighted iterated radial operators between different weighted Bergman spaces on the unit ball, Appl. Math. Comput. 218, 17 (2012), 8288-8294.

[31] S. SteVIĆ, A. K. Sharma, Iterated differentiation followed by composition from Bloch-type spaces to weighted BMOA spaces, Appl. Math. Comput. 218, 7 (2011), 3574-3580.

[32] S. STEVIĆ, S. I. UEKI, Integral-type operators acting between weighted-type spaces on the unit ball, Appl. Math. Comput. 215, 7 (2009), 2464-2471.

[33] X TANG, Extended Ces à ro operators between Bloch-type spaces in the unit ball of $\mathbb{C}^{n}$, J. Math. Anal. Appl. 326, 2 (2007), 1199-1211.

[34] W. YANG, Products of composition and differentiation operators from $Q_{K}(p, q)$ spaces to Bloch-type spaces, Abstr. Appl. Anal. 2009 (2009), Article ID 741920, 14 pp.

[35] X. Zhang, J. XIAO, Z. Hu, The multipliers between the mixed norm spaces in $\mathbb{C}^{n}$, J. Math. Anal. Appl. 311, 2 (2005), 664-674.

[36] K. ZHU, Spaces of Holomorphic Functions in the Unit Ball, Graduate Text in Mathematics 226, Springer, New York, 2005.

[37] X. ZHU, Products of differentiation, composition and multiplication from Bergman type spaces to Bers type spaces (English summary), Integral Transforms Spec. Funct. 18, 3/4 (2007), 223-231.

[38] X. ZHU, Integral-type operators from iterated logarithmic Bloch spaces to Zygmund-type spaces, Appl. Math. Comput. 215, 3 (2009), 1170-1175. 